Please do not remove this page

RMIT

UNIVERSITY

\title{
Transmission expansion planning considering energy storage
}

MacRae, Cameron; Ozlen, Melih; Ernst, Andreas

https://researchrepository.rmit.edu.au/esploro/outputs/9921862277201341/filesAndLinks?institution=61RMIT_INST\&index=null

MacRae, C., Ozlen, M., \& Ernst, A. (2014). Transmission expansion planning considering energy storage. Proceedings of 2014 IEEE International Autumn Meeting on Power, Electronics and Computing (ROPEC 2014), 1-5. https://doi.org/10.1109/ROPEC.2014.7036327

Document Version: Accepted Manuscript

Published Version: https://doi.org/10.1109/ROPEC.2014.7036327

Repository homepage: https://researchrepository.rmit.edu.au (C) 2014 IEEE

Downloaded On 2023/04/27 01:06:09 +1000

Please do not remove this page 
Thank you for downloading this document from the RMIT Research Repository.

The RMIT Research Repository is an open access database showcasing the research outputs of RMIT University researchers.

RMIT Research Repository: http://researchbank.rmit.edu.au/

\section{Citation:}

MacRae, C, Ozlen, M and Ernst, A 2014, 'Transmission expansion planning considering energy storage', in J. A. Marin (ed.) Proceedings of 2014 IEEE International Autumn Meeting on Power, Electronics and Computing (ROPEC 2014), United States, 5-7 November 2014, pp. 1-5.

See this record in the RMIT Research Repository at:

https://researchbank.rmit.edu.au/view/rmit:29532

Version: Accepted Manuscript

Copyright Statement: (C) 2014 IEEE

Link to Published Version:

http://dx.doi.org/10.1109/ROPEC.2014.7036327 


\title{
Transmission Expansion Planning Considering Energy Storage
}

\author{
C.A.G. MacRae ${ }^{* 1}$, M. Ozlen ${ }^{1}$, and A.T. Ernst ${ }^{2}$ \\ ${ }^{1}$ School of Mathematical and Geospatial Sciences, RMIT University \\ ${ }^{2}$ CSIRO, Australia
}

\begin{abstract}
In electricity transmission networks, energy storage systems (ESS) provide a means of upgrade deferral by smoothing supply and matching demand. We develop a mixed integer programming (MIP) extension to the transmission network expansion planning (TEP) problem that considers the installation and operation of ESS as well as additional circuits. The model is demonstrated on the well known Garver's 6-bus and IEEE 25-bus test circuits for two 24 hour operating scenarios; a short peak, and a long peak. We show optimal location and capacity of storage is sensitive not only to cost, but also variability of demand in the network.
\end{abstract}

Keywords - power transmission, energy storage, optimization

\section{Introduction}

The objective of electrical transmission network expansion planning (TEP) is typically to minimize the operational and investment costs of transmission network infrastructure, such as transmission lines or transformers while meeting demand, capacity, security, geographical, or environmental constraints [11. If the planner is concerned only with determining the final long term network plan, the planning is considered static. Whereas if the planner wishes to determine one or more intermediate network plans, perhaps over multiple time periods, the planning is considered dynamic.

The current interest in renewable energy, and wind generation in particular, requires strategies to integrate these often variable forms of generation into the electrical grid [8, 13]. Energy storage systems (ESS) provide a way of smoothing the supply and matching the demand in the network. Hydro, the most common form of storage for large amounts of energy, is relatively cheap but limited by geography. However, other forms of storage (various types of batteries, compressed air, etc.) may also be feasible but significantly more expensive.

In this paper, we develop a model for static TEP in order to determine the minimum capacity (cost) of storage that is required, the location of the storage in the electricity grid, and how this storage should be used, taking into account some of the multiple uses of storage:

\footnotetext{
*Email: cameron.macrae@rmit.edu.au; Corresponding author
} 
1. Demand shifting: storing energy over a period of hours or a day or two in order to match the availability of power with periods of demand.

2. Transmission upgrade deferral: storing energy close to sources of generation or demand and moving it at a steady rate to avoid the need for larger capacity or additional transmission lines.

The TEP problem is often formulated as a mixed integer nonlinear program (MINLP) or as an equivalent disjunctive mixed integer linear program (MIP). An overview of the standard models and test systems is given in [16].

Modern commercial solvers, such as IBM ILOG CPLEX, solve small, linear TEP instances to optimality quickly. However, numerous specialist solution methods have been developed including branch and bound with a GRASP metaheuristic [2, Projection-Adapted Cross Entropy [6], heuristic methods [12], and various evolutionary algorithms [4, 18].

As the problems tend to elegantly decompose into investment and operational sub-problems, decomposition algorithms appear frequently in the literature. Benders decomposition with investment sub-problems with continuous or discrete decision variables, and transportation and DC approximation operation sub-problems are compared in [14. Additional constraints on new paths, and fencing constraints added to the investment sub-problem are shown to reduce the number of iterations required substantially [9]. Gomory cuts have been added at each iteration to solve the linear disjunctive MIP model [3].

The transmission network typically employs high-voltage three-phase alternating current $(\mathrm{AC})$ transmission lines. Given the computational complexity of modelling $\mathrm{AC}$ power flow a linear direct current (DC) approximation model is usually sufficient for the purposes of long term expansion network planning. However, recent research has also considered AC power models [15, 19.

An extension to the disjunctive TEP formulation that considers the location of ESS is developed by Hu et. al [10. Their iterative algorithm first solves the TEP problem without storage, setting an upper bound on the total investment amount. A constant $\bar{z}$, denoting the maximum number of ESS to consider, is set to a value appropriate for the system size. The TEP problem is again solved with a maximum of $\bar{z}$ storage units. If the result is different to the original solution and $\bar{z}>1$, then $\bar{z}$ is decremented by 1 and another solution is obtained, otherwise the algorithm terminates and the set of expansion plans are analyzed.

For Garver's 6-bus test system [7] the algorithm achieves a substantial investment reduction as the model considers energy storage as another form of generation and it is cheaper to add this generation capacity than to install new circuits.

Our approach is significantly different: By introducing discrete time into the model the ESS may be operated like a rechargeable battery, that is, alternately as an energy demand centre or an energy generator.

The installation of ESS is not limited to transmission grids, and consequently has also recently been considered in distribution network planning [17.

The following notation will be used throughout this paper: 
$n_{i j}^{0} \quad$ number of existing circuits on right of way $i j$;

$\bar{n}_{i j} \quad$ maximum number of installable circuits on right of way $i j$;

$y_{i j}^{p} \quad$ binary variable denoting installation of the $p^{\text {th }}$ candidate circuit on right of way $i j$;

$x_{k} \quad$ storage capacity installed at bus $k$;

$\bar{x}_{k} \quad$ maximum installable storage capacity at bus $k$;

$c_{i j} \quad$ cost of installing a circuit on right of way $i j$;

$b_{k} \quad$ cost of installing storage at bus $k$;

$\alpha_{t k} \quad$ cost of curtailment at time $t$ at bus $k$;

$S^{0} \quad$ branch-node incidence matrix of existing circuits;

$S^{c} \quad$ branch-node incidence matrix of candidate circuits;

$f_{t i j}^{0} \quad$ power flow for existing circuits at time $t$ on right of way $i j$;

$f_{t}^{0} \quad$ vector of power flows for existing circuits at time $t$ with elements $f_{t i j}^{0}$;

$f_{t i j}^{p} \quad$ power flow for the $p^{\text {th }}$ candidate circuit at time $t$ on right of way $i j$;

$f_{t}^{c} \quad$ vector of power flows for candidate circuits at time $t$ with elements $f_{t i j}^{p}$;

$\bar{f}_{i j} \quad$ maximum possible power flow on right of way $i j$;

$g_{t k} \quad$ generation at time $t$ at bus $k$;

$g_{t} \quad$ vector of generation at time $t$ with elements $g_{t k}$;

$\bar{g}_{k} \quad$ maximum possible generation at bus $k$;

$\beta_{t k} \quad$ power flow to storage at bus $k$ at time $t$;

$\beta_{t} \quad$ vector of power flow to installed storage at time $t$ with elements $\beta_{t k}$;

$r_{t k} \quad$ demand curtailment at time $t$ at bus $k$;

$r_{t} \quad$ vector of curtailment at time $t$ with elements $r_{t k}$;

$d_{t k} \quad$ vector of demand at time $t$ at bus $k$;

$d_{t} \quad$ vector of demand at time $t$;

$l_{t k} \quad$ level of storage installed at bus $k$ at time $t$;

$\bar{l}_{k} \quad$ maximum possible level of storage installed at bus $k$;

$M_{i j} \quad$ the disjunctive parameter for right of way $i j$

$\gamma_{i j} \quad$ susceptance of circuits installed on right of way $i j$;

$\theta_{t k} \quad$ phase angle at time $t$ at bus $k$;

$\Omega_{0} \quad$ the set of rights of way for existing circuits;

$\Omega_{c} \quad$ the set of rights of way for candidate circuits;

$\Gamma \quad$ the set of indices for buses;

$\Psi \quad$ the set of time periods $\{1,2, \ldots, T\}$;

The rest of this paper is organized as follows. A MIP formulation of the TEP with storage model is given in Section 2. In Sections 3 and 4 we provide two case studies in which we test the model on the Garver's 6-bus and IEEE 25 -bus test systems. We conclude our discussion in Section 5 .

\section{Mathematical Model}

The objective is to minimize the investment costs incurred through installation of new circuits or reinforcing circuits on a right of way, to select and locate storage within the network, and to minimize operational costs which are modelled as a penalty for load curtailment. The model will install storage if it is cheaper to install ESS than to install one or more new circuits.

As noted in Section 1 it is possible to reformulate the classical nonlinear DC approximation model in an equivalent disjunctive mixed integer linear programming form. We extend the disjunctive TEP model to consider the installation 
of ESS:

Minimize:

$$
v=\sum_{(i, j)} c_{i j} y_{i j}^{p}+\sum_{k \in \Gamma} b_{k} x_{k}+\sum_{t \in \Psi} \sum_{k \in \Gamma} \alpha_{t k} r_{t k}
$$

Subject to:

$$
\begin{aligned}
& S^{0} f_{t}^{0}+S^{c} f_{t}^{c}+g_{t}+r_{t}-\beta_{t}=d_{t} \quad \forall t \in \Psi \\
& f_{t i j}^{0}-\gamma_{i j} n_{i j}^{0}\left(\theta_{t i}-\theta_{t j}\right)=0 \\
& \forall t \in \Psi, \forall(i, j) \in \Omega_{0} \\
& \left|f_{t i j}^{p}-\gamma_{i j}\left(\theta_{t i}-\theta_{t j}\right)\right| \leq M_{i j}\left(1-y_{i j}^{p}\right) \\
& \forall t \in \Psi, \forall(i, j) \in \Omega_{c}, \forall p \in\left\{1 \ldots \bar{n}_{i j}\right\} \\
& \left|f_{t i j}^{0}\right| \leq n_{i j}^{0} \bar{f}_{i j} \quad \forall t \in \Psi, \forall(i, j) \in \Omega_{0} \\
& \left|f_{t i j}^{p}\right| \leq y_{i j}^{p} \bar{f}_{i j} \\
& \forall t \in \Psi, \forall(i, j) \in \Omega_{c}, \forall p \in\left\{1 \ldots \bar{n}_{i j}\right\} \\
& l_{1 k}=l_{T k}+\beta_{1 k} \quad \forall k \in \Gamma \\
& l_{t k}=l_{t-1, k}+\beta_{t k} \quad \forall t \in \Psi, \forall k \in \Gamma \\
& 0 \leq l_{t k} \leq x_{k} \quad \forall t \in \Psi, \forall k \in \Gamma \\
& 0 \leq x_{k} \leq \bar{x}_{k} \quad \forall k \in \Gamma \\
& 0 \leq g_{t k} \leq \bar{g}_{k} \quad \forall t \in \Psi, \forall k \in \Gamma \\
& 0 \leq r_{t k} \leq d_{t k} \quad \forall t \in \Psi, \forall k \in \Gamma \\
& y_{i j}^{p} \geq y_{i j}^{p+1} \quad \forall(i, j) \in \Omega_{c}, \forall p \in\left\{1 \ldots \bar{n}_{i j}-1\right\} \\
& y_{i j}^{p} \in\{0,1\} \\
& f_{t i j}^{0}, f_{t i j}^{p}, \beta_{t k}, \theta_{t k} \text { unbounded }
\end{aligned}
$$

In order to model the operation of ESS, it is necessary to introduce discrete time $t$ into the model. Constraint (2) ensures node balance i.e., Kirchhoff's current law at each time period, while Kirchhoff's voltage law is implemented for existing circuits by (3), and for new circuits by the disjunctive constraint (4). In this constraint the disjunctive parameter $M_{i j}$ is a number large enough not to artificially limit the difference in phase angles of buses $i$ and $j$, but 
small enough not to cause numerical instability in the solver. A procedure for calculating minimum values of $M_{i j}$ is given in [3]. Power flow limits are enforced on existing and candidate circuits by (5) and (6).

The operation of the ESS over the time period $t \in\{1,2, \ldots, T\}$ is implemented by constraints (77)-(10). For simplicity, we assume that any selected ESS begins and ends in the same state. This "wrap around" constraint is implemented by (7). For all other time periods the storage level is given by (8). Constraint (9) ensures the stored energy does not exceed the installed capacity.

Bounds on generation and curtailment at each bus are enforced by constraints (11) and (12).

The inclusion of the binary decision variables introduces undesirable symmetry into the model. This can be eliminated by the lexicographical constraint (13).

\section{$2.1 \quad$ Limitations}

In this formulation it is assumed that the operating cost of ESS is negligible. The model could be extended to include operating costs if required, and further extended to consider fixed costs resulting from the installation of storage irrespective of capacity.

Power flows into and out of ESS are limited only by the capacity and level of storage. It is possible that the storage completely charge or discharge within a single time period. Furthermore, the model assumes 100\% efficiency for storage and losses are not considered.

The model also assumes generator re-dispatch is without cost. Future models will likely include a penalty function to address this.

\section{Case Study: Garver's 6-bus Test System}

We test the model using Garver's ubiquitous 6-bus test system. The system has 6 buses, 15 rights of way, and generation and demand are matched at 760MW. The initial network topology and optimal transmission expansion plan without considering ESS are shown in Fig. 1 1 and Fig. 2] respectively. This plan requires an investment of US $\$ 200,000$, and delivers a transmission network capable of satisfying peak load of $760 \mathrm{MW}$ without load curtailment. Four new circuits are installed on right of way $2-6$, two new circuits on right of way $4-6$, and one reinforcing circuit is installed on right of way $3-5$.

Transmission expansion planning typically considers only peak demand in the network. However, we assume that any installed ESS will store energy during periods of low demand and export energy during periods of high demand, and therefore require variable demand in the network over time. For this case study, we consider two different demand scenarios: a short peak scenario and a long peak scenario. Each demand scenario comprises a period of 24 hours with a 30 minute time step.

Fig. 3 shows demand over time in the entire network for each scenario. The short peak scenario is characterized by low demand over the first 5 hours, building steadily over the next 11 hours to a peak of $760 \mathrm{MW}$, before decreasing to more moderate levels. Over the 24 hour time period this scenario has mean demand of $577 \mathrm{MW}$. The long peak is likewise characterized by low demand over 


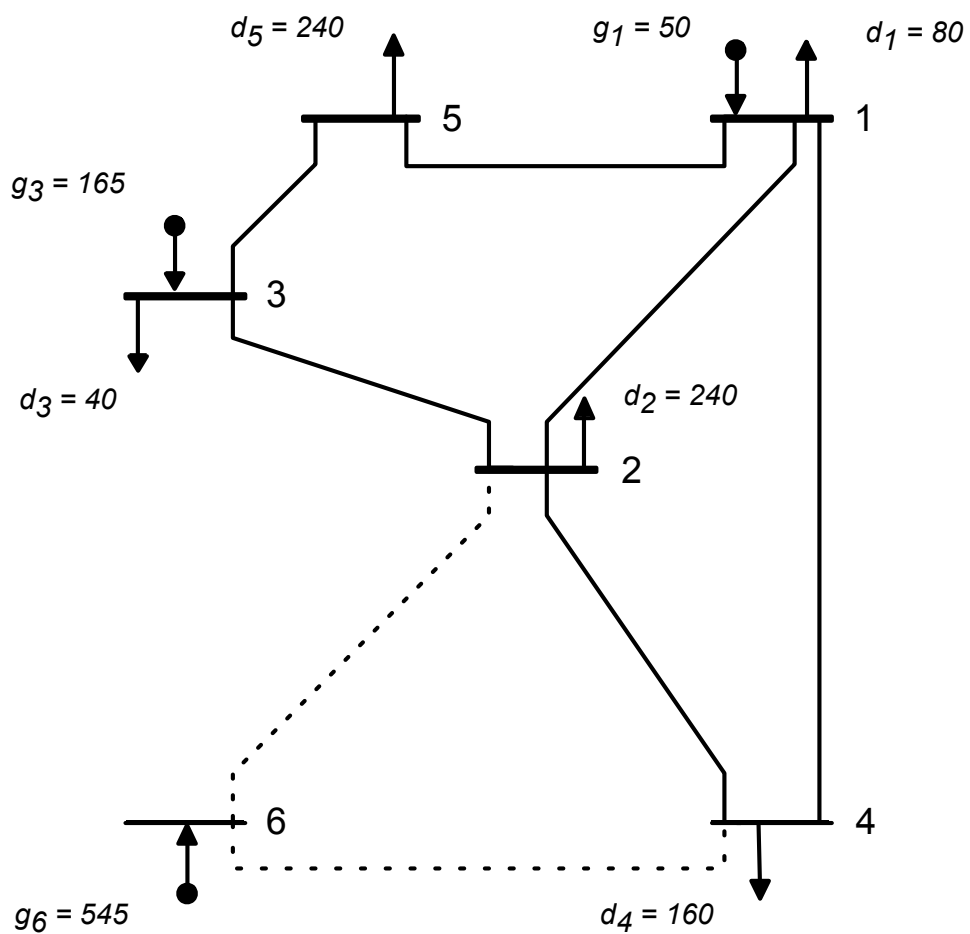

Figure 1: Initial network topology of for Garver's 6-bus test system.

the first 5 hours. Demand then rapidly increases to a peak of $760 \mathrm{MW}$ remaining somewhat constant for the next 10 hours, before moderating over the remainder of the day. In this scenario, mean demand over 24 hours is $670 \mathrm{MW}$.

We apply a single scenario to relatively re-scale demand at all buses, but multiple scenarios can also be handled by this approach.

We allow the installation of ESS with capacity of at most $500 \mathrm{MWh}$ at all 6 buses. This is not a requirement of the formulation and the modeller is free to restrict which buses are candidates for ESS installation as well as the maximum capacity of any installed ESS.

The cost per MW of long term ( $\sim 4$ hours) energy storage, such as pumped hydro or flow batteries, was estimated to be $\operatorname{AUD} \$ 810,451$ (US\$842,058) in 2012 [1, p.43]. The 6-bus test system is particularly useful for verifying the correctness of a model, but its specification and topology is such that using real world cost coefficients for ESS means storage is not selected for the expansion plan. In fact, the real-world cost of installing $1 \mathrm{MWh}$ of storage exceeds the cost of the optimal expansion plan without storage. In order to find a range of cost coefficients that result in ESS installation we solve the model with an initial cost of US $\$ 10 / \mathrm{MWh}$, record the total ESS capacity installed, and increase the cost in US $\$ 10 /$ MWh increments until US $\$ 200 /$ MWh (equivalent to $10^{3} \$ 0.1 \times x_{k}$ ).

Fig. 4 shows the total capacity of ESS installed in the 6-bus system against the cost coefficients. Tabulated data for the breaks are given in Table 1 . 


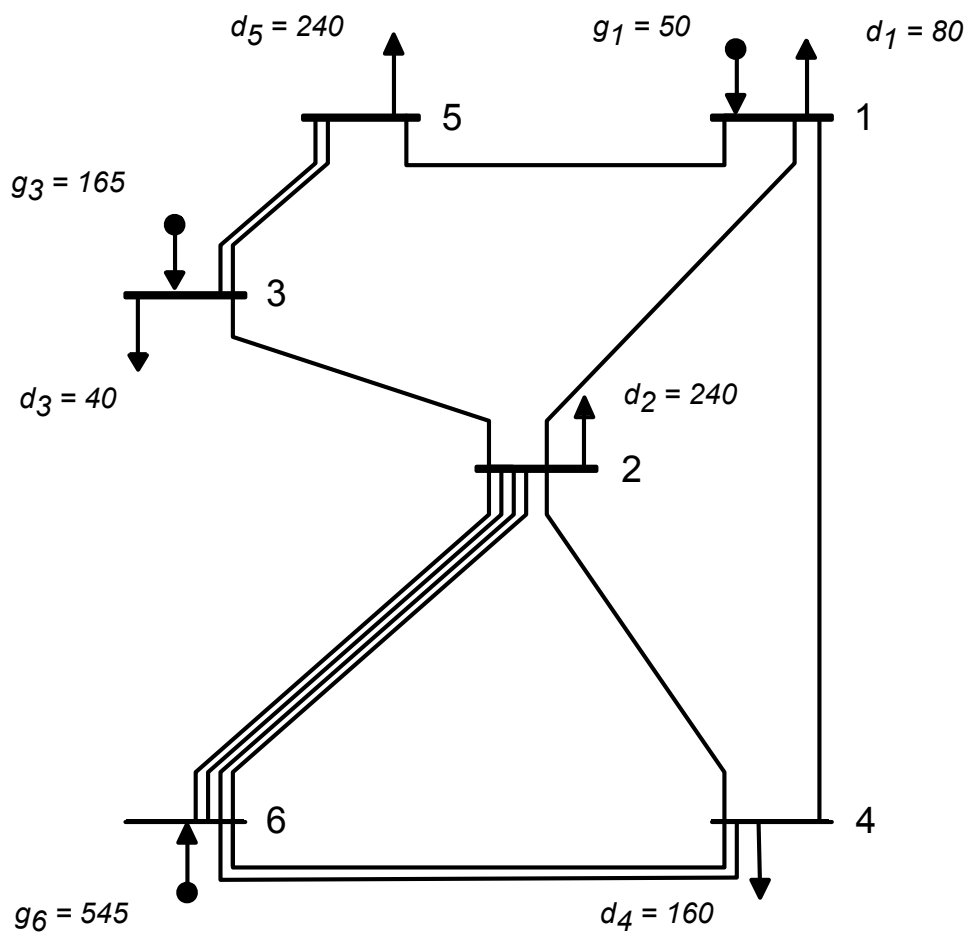

Figure 2: Optimal expansion plan without considering ESS.

Because the relative demand in the system is consistently higher for the long peak scenario than the short peak scenario, storage is not installed until it is of a comparatively low cost. No storage is installed until the cost reaches US $\$ 70 / \mathrm{MWh}$ and even then there is minimal reduction of the total cost after the installation of $420 \mathrm{MWh}$ capacity. For the short peak scenario ESS are installed at the higher cost of US $\$ 170 / \mathrm{MWh}$, but the improvement of the objective function is similarly small. In each case the same new and reinforcing circuits are installed. This suggests that the viability of deploying ESS as a means of transmission upgrade deferral is at least in part dependent on the nature of the demand during the time period in which the storage is operated, but the most significant factor is cost.

The final expansion plan under the short peak scenario with storage cost of US\$170/MWh is given in Fig. 5. Installing ESS with capacity of $175 \mathrm{MWh}$ enables the installation of 1 circuit on right of way $2-6$ to be deferred. The cost of the network expansion is reduced by US $\$ 250$. 


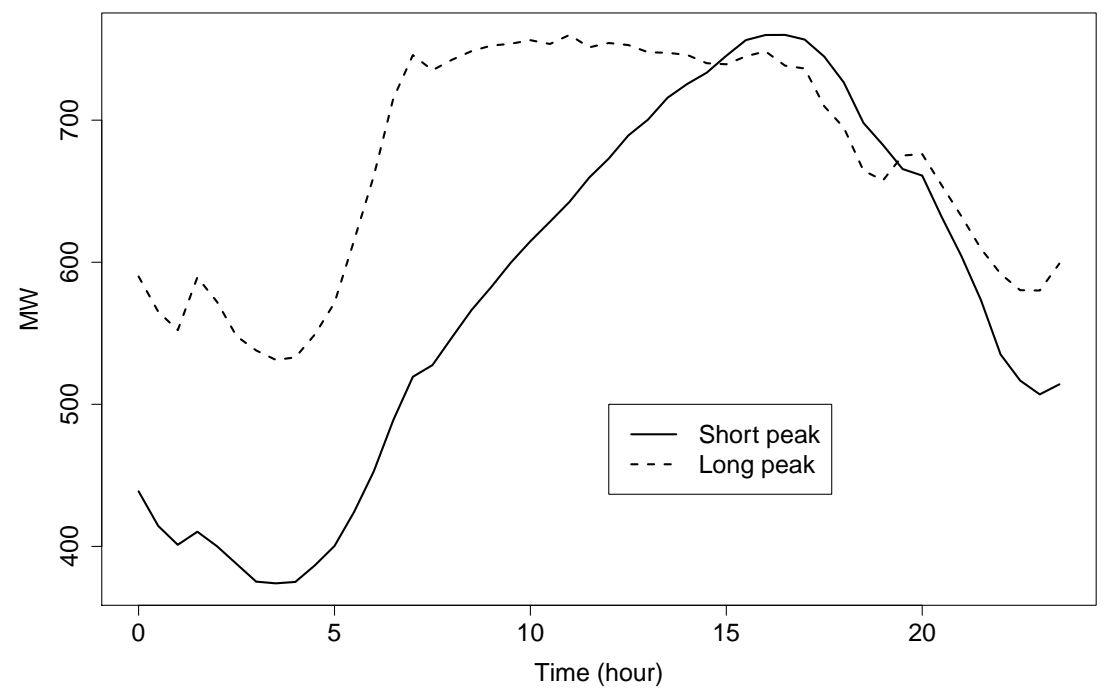

Figure 3: Demand over time for short peak and long peak scenarios.

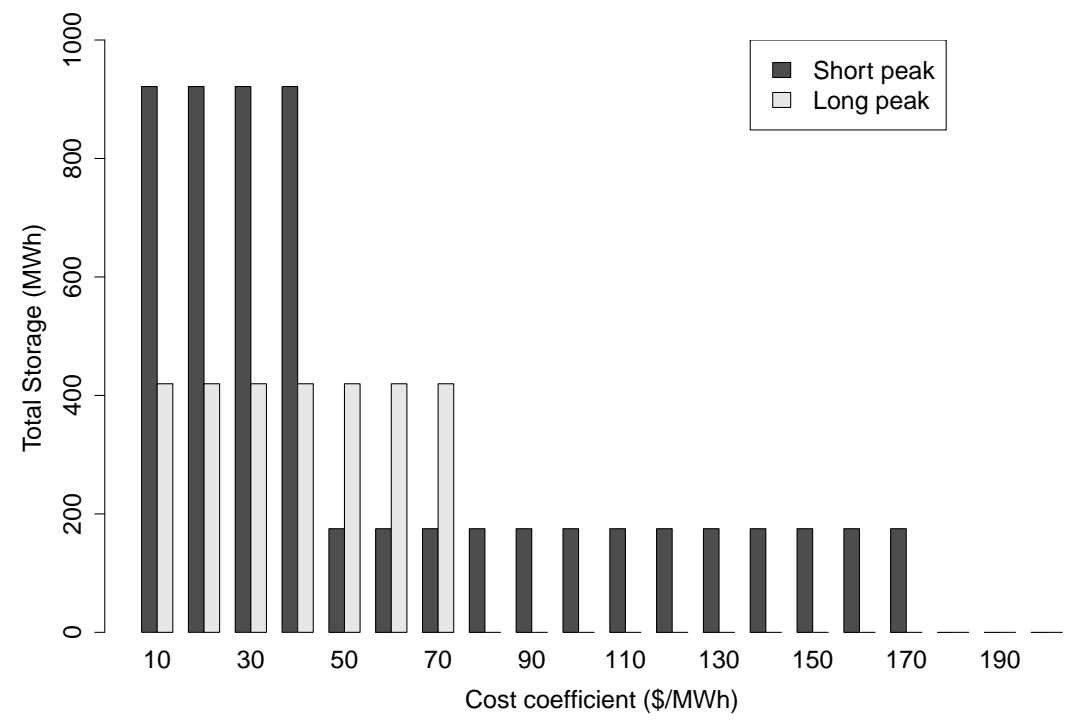

Figure 4: ESS cost coefficient breaks for Garver's 6-bus network. 
Table 1: Storage cost coefficient breaks for Garver's 6-bus network.

\begin{tabular}{|c|c|c|c|c|}
\hline Scenario & $\begin{array}{l}\text { Storage Cost } \\
\text { (US } \$ / M W h)\end{array}$ & $\begin{array}{c}\text { Total Cost } \\
\left(\mathrm{US} \$ 10^{3}\right)\end{array}$ & Circuits & $\begin{array}{c}\text { Total Storage } \\
(\mathrm{MWh})\end{array}$ \\
\hline \multirow[t]{3}{*}{ Short peak } & 200 & 200.00 & $\begin{array}{l}2-6(4) \\
3-5(1) \\
4-6(2)\end{array}$ & 0 \\
\hline & 170 & 199.75 & $\begin{array}{l}2-6(3) \\
3-5(1) \\
4-6(2)\end{array}$ & 175 \\
\hline & 40 & 176.86 & $\begin{array}{l}2-6(4) \\
3-5(1)\end{array}$ & 921 \\
\hline \multirow[t]{2}{*}{ Long peak } & 200 & 200.00 & $\begin{array}{l}2-6(4) \\
3-5(1) \\
4-6(2)\end{array}$ & 0 \\
\hline & 70 & 199.38 & $\begin{array}{l}2-6(3) \\
3-5(1) \\
4-6(2)\end{array}$ & 420 \\
\hline
\end{tabular}

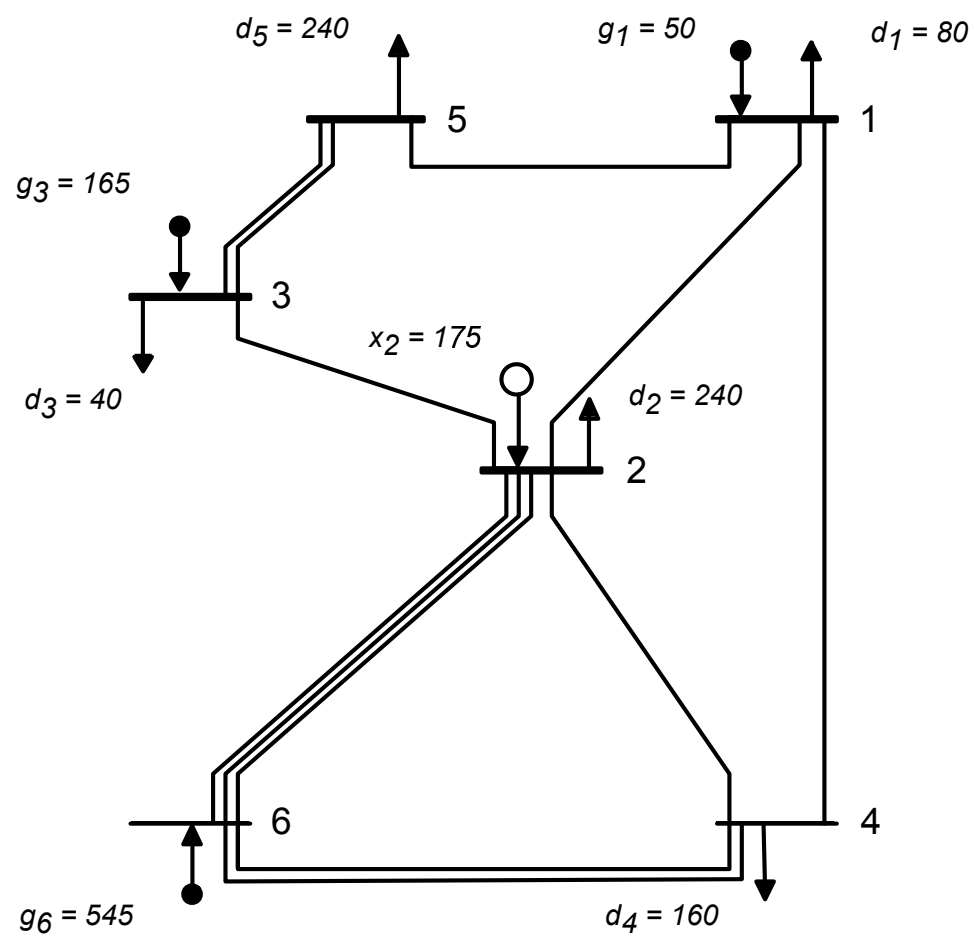

Figure 5: Transmission expansion plan for 6-bus network for short peak scenario and storage cost US $\$ 170 / \mathrm{MWh}$ 


\section{Case Study: IEEE 25-bus Test System}

The IEEE 25-bus test system is an extension to the IEEE 24-bus reliability network. The tabulated data and diagram are available in [5]. The system has 25 buses, 36 rights of way, and total demand of $2750 \mathrm{MW}$. If a maximum of 4 new circuits are allowed on each right of way, the optimal expansion plan without storage has a cost of US $\$ 107.7$ million (see Table 2 for circuit additions).

For this case study we use the short peak and long peak scenarios discussed in Section 3, and demand re-scaling occurs at each bus as before. As we wish only to demonstrate the use of the model the fictitious cost coefficient of 1.0 is used for ESS, which given the 30 minute time step is equivalent to $\$ 2000 / \mathrm{MWh}$. The model is solved using IBM ILOG CPLEX 12.6 on a cluster node with 16 cores of Intel E5-2670 and 32GB of RAM. Numerical results are given in Table2.

Table 2: Results for IEEE 25-bus network.

\begin{tabular}{|c|c|c|c|c|c|}
\hline Scenario & $\begin{array}{l}\text { Storage Cost } \\
(\mathrm{US} \$ / \mathrm{MWh})\end{array}$ & $\begin{array}{c}\text { Obj. } \\
\left(\mathrm{US} \$ 10^{3}\right)\end{array}$ & Circuits & $\begin{array}{c}\text { Total Storage } \\
\text { (MWh) }\end{array}$ & $\begin{array}{c}\text { Wall Time } \\
(\mathrm{s})\end{array}$ \\
\hline No storage & - & 107706 & $\begin{array}{l}1-2(1) \\
7-13(1) \\
8-22(3) \\
12-14(2) \\
12-23(3) \\
13-18(2) \\
13-20(4) \\
24-25(2)\end{array}$ & 0 & 3.54 \\
\hline Short peak & 2000 & 39405 & $\begin{array}{l}5-25(2) \\
7-16(1) \\
8-22(1) \\
12-23(1) \\
13-18(1)\end{array}$ & 2103 & 176787 \\
\hline Long peak & 2000 & 67221 & $\begin{array}{l}5-25(2) \\
8-22(3) \\
12-14(1) \\
12-23(2) \\
13-18(1) \\
13-20(1)\end{array}$ & 1432 & 51850 \\
\hline
\end{tabular}

For the long peak scenario a total of 10 new circuits on 6 rights of way are combined with $1432 \mathrm{MWh}$ of energy storage at a cost of US\$67.2 million. As for Garver's 6-bus test system, more storage is installed for the short peak scenario with 2103 MWh of storage installed alongside 6 new circuits on 5 rights of way at a total cost of US\$39.4 million.

If storage is not considered the model need only solve a single time period and the solution time is very fast $(<4 \mathrm{~s})$. When ESS and time periods are introduced the complexity of the model greatly increases as generation output, power flows, bus phase angles, and storage levels must be calculated for each time period. As a consequence wall time increases significantly to 14.4 hours for 
the long peak scenario, and 49.1 hours for the short peak scenario. The model is also sensitive to network size, and preliminary numerical results for a 46-bus network 9] have shown that the problem cannot be solved within 7 days.

\section{Conclusion}

In this paper we have shown how the TEP can be extended to consider ESS as a means of transmission upgrade deferral. The model has been tested against the well known Garver's 6-bus and IEEE 25-bus test systems under two different demand scenarios.

Our results show storage unlikely to be chosen where circuit installation is of comparatively low cost, and that the amount of storage installed is dependent on the demand scenario under which it is operated.

We find the model becomes computationally demanding with even relatively few buses.

\section{Acknowledgment}

The second author is supported by the Australian Research Council under the Discovery Projects funding scheme (project DP140104246).

\section{References}

[1] Energy storage in australia. commercial opportunities, barriers and policy options. Technical Report Version 1, Marchment Hill Consulting, November 2012.

[2] L. Bahiense, G.C. Oliveira, M. Pereira, and S. Granville. A mixed integer disjunctive model for transmission network expansion. IEEE Transactions on Power Systems, 16(3):560-565, 2001.

[3] S. Binato, M. V F Pereira, and S. Granville. A new benders decomposition approach to solve power transmission network design problems. IEEE Transactions on Power Systems, 16(2):235-240, 2001.

[4] I. De J Silva, M.J. Rider, R. Romero, A.V. Garcia, and C.A. Murari. Transmission network expansion planning with security constraints. Generation, Transmission and Distribution, IEEE Proceedings-, 152(6):828-836, 2005.

[5] AO. Ekwue and B.J. Cory. Transmission system expansion planning by interactive methods. IEEE Transactions on Power Apparatus and Systems, PAS-103(7):1583-1591, July 1984.

[6] Ali Eshragh, Jerzy Filar, and Asef Nazari. A projection-adapted cross entropy (PACE) method for transmission network planning. Energy Systems, 2(2):189-208, May 2011.

[7] L.L. Garver. Transmission network estimation using linear programming. IEEE Transactions on Power Apparatus and Systems, PAS-89(7):16881697, 1970. 
[8] Yang Gu, J.D. McCalley, and Ming Ni. Coordinating large-scale wind integration and transmission planning. IEEE Transactions on Sustainable Energy, 3(4):652-659, 2012.

[9] S. Haffner, A. Monticelli, A. Garcia, J. Mantovani, and R. Romero. Branch and bound algorithm for transmission system expansion planning using a transportation model. Generation, Transmission and Distribution, IEEE Proceedings-, 147(3):149-156, 2000.

[10] Zechun Hu, Fang Zhang, and Baowei Li. Transmission expansion planning considering the deployment of energy storage systems. In 2012 IEEE Power and Energy Society General Meeting, pages 1-6, 2012.

[11] G. Latorre, R.D. Cruz, J.M. Areiza, and A. Villegas. Classification of publications and models on transmission expansion planning. IEEE Transactions on Power Systems, 18(2):938-946, 2003.

[12] G. Latorre-Bayona and I.J. Perez-Arriaga. CHOPIN, a heuristic model for long term transmission expansion planning. IEEE Transactions on Power Systems, 9(4):1886-1894, 1994.

[13] G.A. Orfanos, P Georgilakis, and N.D. Hatziargyriou. Transmission expansion planning of systems with increasing wind power integration. IEEE Transactions on Power Systems, 28(2):1355-1362, 2013.

[14] M. V F Pereira, L. M V G Pinto, S. H F Cunha, and G.C. Oliveira. A decomposition approach to automated generation/transmission expansion planning. IEEE Transactions on Power Apparatus and Systems, PAS104(11):3074-3083, 1985.

[15] M.J. Rider, AV. Garcia, and R. Romero. Power system transmission network expansion planning using AC model. IET Generation, Transmission Distribution, 1(5):731-742, September 2007.

[16] R. Romero, A. Monticelli, A. Garcia, and S. Haffner. Test systems and mathematical models for transmission network expansion planning. Generation, Transmission and Distribution, IEEE Proceedings-, 149(1):27-36, 2002.

[17] M. Sedghi, M. Aliakbar-Golkar, and M.-R. Haghifam. Distribution network expansion considering distributed generation and storage units using modified PSO algorithm. International Journal of Electrical Power \& Energy Systems, 52:221-230, November 2013.

[18] Thanathip Sum-Im. A novel differential evolution algorithmic approach to transmission expansion planning. Thesis, Brunel University School of Engineering and Design PhD Theses, 2009. This thesis was submitted for the degree of Doctor of Philosophy and awarded by Brunel University.

[19] J.A. Taylor and F.S. Hover. Linear relaxations for transmission system planning. IEEE Transactions on Power Systems, 26(4):2533-2538, 2011. 